\title{
An Analysis on the Preference of Early Childhood Teachers in Horticultural Activities Based on Conjoint Analysis
}

\author{
Yeojin Jeong ${ }^{1}$, Mijin $\mathrm{Kim}^{2}$, Taegwon Chang ${ }^{3}$, and Sukyoung Yun ${ }^{4}$ \\ ${ }^{1}$ Doctoral student, Department of horticulture, The graduate school, Daegu Catholic University, Gyeongsan 38430, South Korea \\ ${ }^{2}$ CEO, Mellia, Susung gu, Daegu 42019, South Korea \\ ${ }^{3}$ Professor, Department of Advertising \& Public Relations, Daegu Catholic University, Gyeongsan 38430, South Korea \\ ${ }^{4}$ Professor, Department of Horticulture, Daegu Catholic University, Gyeongsan 38430, South Korea
}

\section{ABSTRACT}

Background and objective: This study conducted a conjoint analysis on early childhood teachers to find out their preferences in horticultural activities that are used as a means of education in early childhood education.

Methods: For the conjoint analysis, five attributes of horticultural activities were selected. Attribute 1 was method of horticultural activities, divided into two levels: exclusive and integrated horticultural activities. Attribute 2 was object of horticultural activities, divided into three levels: fruit crops, vegetable crops, and floricultural crops. Attribute 3 was activity type, divided into three levels: big and small group, free choice, and outdoor play. Attribute 4 was place for horticultural activities, and divided into two levels: indoors and outdoors. Attribute 5 was time for horticultural activities, divided into two levels: 30 minutes and 30-60 minutes. The orthogonal design was used to extract 20 profiles, after which we conducted a survey on 320 early childhood teachers and analyzed the valid responses from 257 teachers.

Results: The preference of early childhood teachers showed highest importance in object (29.1\%), followed by activity type (23.2\%), activity method (17.4\%), time (16.1\%), and place (14.2\%) (Pearson's $R=.591, p=.008)$. By level of each attribute, the importance was high in exclusive horticultural activities for activity method, big and small group for activity type, vegetable and floricultural crops for object, indoors for place, and 30 minutes for time.

Conclusion: The horticultural program preferred by early childhood teachers is comprised of big and small group activities using vegetable and floricultural crops, carried out indoors for 30 minutes as an exclusive class.

Keywords: attribute, big and small groups, vegetable crops

\section{Introduction}

According to the 'Revised Kindergarten Curriculum 2007' by the Ministry of Education, Science and Technology, the purpose of early childhood education leading the 21st century knowledge and information era is to 'cultivate Koreans that respect and care for people and nature' (Ministry of Education Science and Technology[MEST], 2007). With the awareness that 'nature is the source of education', the need for education in nature is also widely perceived by recent institutions of early childhood education (Lee, 2011).
Early childhood is the period in which the basis of all development areas is formed, and as the value system and attitudes formed in this period affect the life attitudes in the future, it is important to build up an upright character and sociality starting from early childhood, which increases interest in nature-friendly education in early childhood education settings (Kim, 2010).

Studies are actively conducted in Korea regarding nature-friendly education for preschoolers. It is found that an ecological program for early childhood helped preschoolers use their emotions, perceive and care for other people's

Received: July 20, 2020, Revised: September 9, 2020, Accepted: October 1, 2020

First author: Yeojin Jeong, lololo77777@hanmail.net, (1) https://orcid.org/0000-0002-1499-0135

*Corresponding author: Sukyoung Yun, yune1004@cu.ac.kr, (10) https://orcid.org/0000-0002-5862-0021 
emotions, control their feelings and impulse, and improve intelligence (Kang and Park, 2010), and playing in the forest was effective in improving scientific inquiry skills and life respect attitude of preschoolers (Lee and Choi, 2015). Children aged 5 showed improvement in community spirit, intimacy, sense of belonging and participation by playing in the forest (Jang and Chung, 2018), and playing in the forest had a positive effect on reducing daily stress of children aged 4-5 (Lee, 2014). There was also a study determining the reduction of preschoolers' stress after playing in the forest by examining the change in cortisol levels (Yun et al., 2019). Forest activities of preschoolers aged 5 had a significant effect on increasing positive vocabulary and decreasing negative vocabulary of preschoolers (Jang et al., 2019). There are also many other studies summarizing and analyzing findings on the effects of nature-friendly education related to preschoolers, such as a meta-analysis on the effect of preschoolers' forest activities (Cho et al., 2016) and a research trend analysis on forest activities for preschoolers (Kim et al., 2019).

Studies on horticultural activities of preschoolers are conducted in various ways in terms of children's emotional and intellectual aspect. Horticultural activities for preschoolers using green plants as a mediator improved sub-factors of their emotional intelligence with statistical significance, such as using self-emotion and perceiving and considering others' emotions (Jung et. al., 2017), while also having a positive effect on improving preschoolers' emotional intelligence and reducing daily stress (Park and Huh, 2010). Horticultural activities also had effect in improving preschoolers' nature-friendly attitude toward the environment, scientific attitude and inquiry skills, and emotional intelligence (Jeong et al., 2009). Horticultural activities using a four-season ornamental rooftop garden showed a significant effect on preschoolers' intellectual development (Jeong et al., 2014). There are also studies determining the effects of horticultural activities by differentiating the objects used by preschoolers such as kindergarteners' preference of herbal plants (Shin et al., 2012). Horticultural activities of 4-year-old children using colored food vegetables helped children more naturally respond to the colors of the vegetables and fruits than the control group and reduced the tendency to avoid eating vegetables (Son et al., 2015).
Furthermore, there are studies applying horticultural activities in combination with other fields. As a result of implementing an integrated art and horticulture program for preschoolers with physical disabilities, there was a statistically significant difference in improvement of interpersonal relations (Kim, 2015). A meta-analysis on the experimental effects of horticultural programs in the master's and doctoral dissertations in Korea conducted on kindergarteners to high school students showed that the programs relatively had a positive effect, which was especially high in the cognitive function of kindergarteners (Lee and Jeong, 2018). As such, various studies are testing the effects of preschoolers' horticultural activities.

Meanwhile, as a result of analyzing the frequency and content of horticultural activities using 696 activities in 11 teacher's guidebooks for the 5-year-old Nuri Curriculum, it was found that the activities were concentrated on certain life topics mediated by video clips and photos and images of plants rather than real ones based on science, or merely talking indoors in big and small groups, which shows the lack of horticultural activities in the regular curriculum for early childhood (Choi et al., 2020). As suggested by the report that preservice early childhood teachers could overcome the difficulties as a teacher and gain confidence by developing and teaching the 'Forest Character Program' in association with a daycare center that is an institution of industry-education cooperation (Kang, 2016), horticultural activities perceived and experienced by early childhood teachers are important, but there is insufficient research on activities preferred by early childhood teachers.

Therefore, this study sets the attributes and levels of horticultural activities and extracts profiles through the orthogonal design of conjoint analysis. After conducting a survey on kindergarten and daycare center teachers with the profiles, a conjoint analysis is conducted on the results by attribute and level, comprehensively analyzing the preference in horticultural activities. The results are used to determine the early childhood teachers' perception and preference in horticultural activities, thereby providing basic data to implement a horticultural program in the regular curriculum of preschoolers. 


\section{Research Methods}

\section{Questionnaire design}

Conjoint analysis is a typical method used to analyze consumer utility in marketing, predicting the product that will be chosen by the customer by estimating the utility given to each attribute of the product. Conjoint analysis was developed in mathematical psychology and generally refers to the method of mathematically analyzing consumer preferences for multi-attribute stimuli formed by experimental design (Ha, 2012). In conjoint analysis, the subject has a few important attributes, and each attribute is presumed to have a few levels or values. This study conducted a survey on early childhood teachers to implement horticultural activities in the regular curriculum for early childhood education based on the Nuri Curriculum. The survey was conducted online, and demographic characteristics of the subjects and key information of horticultural activities related to early childhood were set considering multiple levels of each attribute for conjoint analysis.

This study set five attributes of horticultural activities for conjoint analysis (Table 1). In the meta-analysis of research papers to verify the effect of horticultural therapy (Jang et al., 2010), the method of horticultural activities was set as growing plants, decorating plants and integrated activities. First, as the method of horticultural activities, growing and decorating plants based on the children's level

Table 1. Attribute and levels of horticultural activities for conjoint analysis

\begin{tabular}{|c|c|c|}
\hline No. & Attribute & Levels \\
\hline \multirow{2}{*}{1} & \multirow{2}{*}{ Activity method } & Horticultural activity \\
\hline & & Integration horticultural activity \\
\hline \multirow{3}{*}{2} & \multirow{3}{*}{ Activity topics } & Large and small group \\
\hline & & Free selection \\
\hline & & Outside play \\
\hline \multirow{3}{*}{3} & \multirow{3}{*}{ Object } & Fruit crops \\
\hline & & Vegetable crops \\
\hline & & Floricultural crops \\
\hline \multirow{2}{*}{4} & \multirow{2}{*}{ Place } & Indoor \\
\hline & & Outdoor \\
\hline \multirow{2}{*}{5} & \multirow{2}{*}{ Time } & $30 \mathrm{~min}$. \\
\hline & & $30 \sim 60 \mathrm{~min}$. \\
\hline
\end{tabular}

was set as the horticultural activity in Attribute 1, and integrated horticultural activities were selected as Level 2, which are activities that integrate other fields like music, art and science with horticultural activities. Attribute 2 is selected based on the types of activities presented in 696 individual activities in 11 teacher's guidebooks by topic in the 5-year-old Nuri Curriculum (Kim and Woo, 2014, Choi et al., 2020). Types of activities were divided into three levels: big and small group type in which children form groups for activities, free choice type in which children can choose the activity they want by giving them options so that they are provided with educationally meaningful activities, and outdoor play type in which they participate in activities outdoors. Attribute 3 was in three levels of fruit crops, vegetable crops, and floricultural crops as the subjects of horticultural activities. Attribute 4 selected two levels of indoors and outdoors as the venue for horticultural activities. Attribute 5 was in two levels of $30 \mathrm{mi}-$ nutes and 30-60 minutes as the time for horticultural activities.

\section{Analyzing the importance of attributes and estimating part worth}

There were total 72 cases $(2 \times 3 \times 3 \times 2 \times 2)$ of profiles that can be presented according to five key attributes such as method, type, object, place, and time as well as the levels of each attribute in the survey, but evaluation is impossible in reality as it is too much pressure for the respondents to evaluate the preference of all these profiles. Therefore, to adequately reduce the number of stimuli, orthogonal design of SPSS statistical program was used to extract total 20 profiles including 4 profiles for verification (holdout) (Table 2). Profiles for verification are included to verify the validity of prediction by comparing the consistency with actually designed profiles (Heo, 2015).

The part-worth function model was applied to estimate the worth of the survey. The part-worth function model measures utility with the assumption that each attribute and level has individual part worth (Ha, 2012), and it was applied as each level of the attributes of horticultural activities can be presumed to have individual part worth (Fig. 1). 
Table 2. Profile properties of horticultural activities

\begin{tabular}{|c|c|c|c|c|c|c|}
\hline Profile no. & Object $^{z}$ & Activity method ${ }^{y}$ & Activity topics ${ }^{\mathrm{x}}$ & Place & Time(minute) & Profile status ${ }^{\mathrm{w}}$ \\
\hline 1 & $\mathrm{Fl}$ & Ih & $\mathrm{F}$ & Outdoor & $30 \sim 60$ & Design \\
\hline 2 & $\mathrm{Fr}$ & $\mathrm{H}$ & $\mathrm{F}$ & Outdoor & $30 \sim 60$ & Design \\
\hline 3 & Ve & $\mathrm{H}$ & Ls & Outdoor & $30 \sim 60$ & Design \\
\hline 4 & Ve & $\mathrm{H}$ & $\mathrm{F}$ & Outdoor & 30 & Design \\
\hline 5 & $\mathrm{Fr}$ & $\mathrm{H}$ & $\mathrm{O}$ & Outdoor & 30 & Design \\
\hline 6 & $\mathrm{Fr}$ & Ih & $\mathrm{O}$ & Outdoor & $30 \sim 60$ & Design \\
\hline 7 & $\mathrm{Ve}$ & Ih & $\mathrm{O}$ & Indoor & $30 \sim 60$ & Design \\
\hline 8 & $\mathrm{Fr}$ & $\mathrm{H}$ & $\mathrm{F}$ & Indoor & 30 & Design \\
\hline 9 & $\mathrm{Fl}$ & $\mathrm{H}$ & $\mathrm{F}$ & Indoor & $30 \sim 60$ & Design \\
\hline 10 & $\mathrm{Fr}$ & Ih & Ls & Indoor & 30 & Design \\
\hline 11 & $\mathrm{Fr}$ & Ih & $\mathrm{F}$ & Indoor & $30 \sim 60$ & Design \\
\hline 12 & Fr & $\mathrm{H}$ & Ls & Indoor & $30 \sim 60$ & Design \\
\hline 13 & $\mathrm{Ve}$ & Ih & $\mathrm{F}$ & Indoor & 30 & Design \\
\hline 14 & $\mathrm{Fr}$ & Ih & $\mathrm{F}$ & Outdoor & 30 & Design \\
\hline 15 & $\mathrm{Fl}$ & Ih & Ls & Outdoor & 30 & Design \\
\hline 16 & $\mathrm{Fl}$ & $\mathrm{H}$ & $\mathrm{O}$ & Indoor & 30 & Design \\
\hline 17 & $\mathrm{Ve}$ & Ih & Ls & Indoor & 30 & Holdout \\
\hline 18 & $\mathrm{Ve}$ & $\mathrm{H}$ & $\mathrm{O}$ & Indoor & $30 \sim 60$ & Holdout \\
\hline 19 & $\mathrm{Ve}$ & $\mathrm{H}$ & $\mathrm{F}$ & Outdoor & $30 \sim 60$ & Holdout \\
\hline 20 & $\mathrm{Fl}$ & Ih & F & Indoor & 30 & Holdout \\
\hline
\end{tabular}

${ }^{\mathrm{z}} \mathrm{FL}=$ floricultural crops; $\mathrm{Fr}=$ fruit crops; $\mathrm{Ve}=$ vegetable crops.

${ }^{\mathrm{y}} \mathrm{Ih}=$ integration horticultural activity; $\mathrm{H}=$ horticultural activity.

${ }^{\mathrm{x}} \mathrm{F}=$ free selection; $\mathrm{Ls}=$ large and small group; $\mathrm{O}=$ outside play.

${ }^{\mathrm{w}}$ Design $=$ profile extracted from orthogonal design; Holdout $=$ profile for verification .

$$
S_{j}=\sum_{P=1}^{t} f_{p}\left(y_{j p}\right)
$$

$s_{j}$ : Preference for product $\mathrm{j}$

$f_{p}$ : Respondent's partial value function for attribute level $y_{j p}$ of attribute $\mathrm{p}$ $y_{i n}$ : Attribute level of attribute $\mathrm{p}$ of product $\mathrm{j}$

Fig. 1. Part-worth function model. Reprinted from "The validity of conjoint models with the attributes and their levels determined by the respondents", by C.S. Ha, 2012, Doctoral dissertation, Kyung Hee University, Suwon, Korea, p. 16.

\section{Survey and analytical procedures}

The survey to implement horticultural activities in the regular early childhood curriculum based on the Nuri Curriculum was conducted on early childhood teachers online for 40 days from May 15 to June 25, 2020. 20 profiles were presented for the teachers to prioritize them based on preference, scoring them 10-9 points if most preferred, 8-7 points if preferred, 6-5 points for neutral, 4-3 points for not preferred, and 2-1 points for least preferred. 257 subjects were used in the final analysis out of 320 respondents, excluding 45 with unclear or insincere responses. Conjoint analysis was conducted after statistical treatment according to the rules of the part-worth function model using IBM SPSS v.19.0 program. Correlation among the attributes was verified by Pearson's correlation coefficient.

\section{Results and Discussions}

\section{Demographic characteristics}

The demographic characteristics of the participants are as follows. 90 participants had 4 years or less experience 
Table 3. Classification of survey respondents

\begin{tabular}{|c|c|c|c|}
\hline Item & Type & $\mathrm{N}(\%)$ & Total number(\%) \\
\hline \multirow{4}{*}{ Years of work experience } & 4 years or less & $90 \quad(35.02)$ & \multirow{4}{*}{$257(100 \%)$} \\
\hline & $5-9$ years & $79(30.74)$ & \\
\hline & More than 10 years & $85 \quad(33.07)$ & \\
\hline & Other $^{2}$ & $3(1.17)$ & \\
\hline \multirow{5}{*}{ Educational level } & Associated Degree & $148 \quad(57.59)$ & \multirow{5}{*}{$257(100 \%)$} \\
\hline & Bachelor's degree & $77(29.96)$ & \\
\hline & Master Degree & $21(8.17)$ & \\
\hline & Doctor Degree & $5(1.95)$ & \\
\hline & Other $^{\mathrm{y}}$ & $6(2.33)$ & \\
\hline \multirow{3}{*}{ Program type } & Public kindergarten & $13(5.06)$ & \multirow{3}{*}{$257(100 \%)$} \\
\hline & Private kindergarten & $126(49.03)$ & \\
\hline & Child Care Center & $118(45.91)$ & \\
\hline \multirow{3}{*}{ Teacher certificate } & Level 1 Orthodox Teacher & $124(48.25)$ & \multirow{3}{*}{$257(100 \%)$} \\
\hline & Level 2 Orthodox teacher & $132(51.36)$ & \\
\hline & Other $^{\mathrm{z}}$ & $1(0.39)$ & \\
\hline \multirow{4}{*}{ Class age } & 3 years & $121(47.08)$ & \multirow{4}{*}{$257(100 \%)$} \\
\hline & 4 years & $51(19.84)$ & \\
\hline & 5 years & $84(32.68)$ & \\
\hline & Other $^{\mathrm{x}}$ & $1 \quad(0.39)$ & \\
\hline
\end{tabular}

Note. $\mathrm{N}=257$.

${ }^{\mathrm{z}}$ Intern teacher, ${ }^{\mathrm{y}}$ During one's bachelor's degree or a two-year college graduate, ${ }^{\mathrm{x}}$ Integrated class of three to five years of age.

(35.02\%), followed by 85 participants with 10 years or more experience (33.07\%), 79 with 5-9 years of experience (30.74\%), and 3 others (1.17\%) (Table 3). Others included interns. 164 participants (63.81\%) had at least 5 years of experience as a teacher, which suggests that they might have responded to the questionnaire with general awareness of horticultural activities. By education level, 148 participants graduated a 2-year or 3-year college (57.59\%), followed by 77 participants who graduated a 4-year college (29.96\%), 21 with a master's degree $(8.17 \%)$, others $(2.33 \%)$, and 5 with a doctoral degree (1.95\%). Others included interns currently attending a 2-year or 4-year college. By type of workplace, 126 participants worked in a private kindergarten $(49.03 \%), 118$ in a daycare center $(45.91 \%)$, and 13 in a public kindergarten $(5.06 \%)$. For teaching certificate, 132 were certified as Teacher Level 2 (51.36\%), 124 as Teacher Level 1 (48.25\%), and 1 other $(0.39 \%)$. Other included an intern teacher who does not have a teaching certificate yet. By class age, 121 participants were teaching the 3-year-old class $(47.08 \%), 84$ teaching the 5-year-old class $(32.68 \%), 51$ teaching the 4-year-old class $(19.84 \%)$, and 1 other $(0.39 \%)$. Other included the case in which the class was run as an integrated class for 3-year-olds and 4-year-olds.

\section{Preference of early childhood teachers by attribute of horticultural activities}

The survey respondents were to choose the activity with highest utility calculated as the sum of part worth by attribute level of each profile selected including the profiles for verification (maximum utility rule) (Heo, 2015). Preference of early childhood teachers by attribute of horticultural activities statistically treated according to the part-worth function model is as shown in Table 4. As a result of analyzing preference of early childhood teachers by attribute of horticultural activities, it was found that importance by attribute was object $29.1 \%$, activity type $23.2 \%$, activity method $17.4 \%$, time $16.1 \%$, and place $14.2 \%$ (Pearson's $\mathrm{R}=.591$, 
Table 4. Preference of horticultural activities for kindergarten teachers.

\begin{tabular}{|c|c|c|c|c|}
\hline Attribute & Levels & Part utility ${ }^{\mathrm{Z}}$ & Importance $(\%)^{\mathrm{y}}$ & Pearson's R $(p)$ \\
\hline \multirow{2}{*}{ Activity method } & Horticultural activity & .076 & \multirow{2}{*}{17.4} & \\
\hline & Integration horticultural activity & -.076 & & \\
\hline \multirow{3}{*}{ Activity topics } & Large and small group & .019 & \multirow{3}{*}{23.2} & \\
\hline & Free selection & -.008 & & \\
\hline & Outside play & -.011 & & \\
\hline \multirow{3}{*}{ Object } & Fruit crops & .021 & \multirow{3}{*}{29.1} & .591 \\
\hline & Vegetable crops & .156 & & $(.008)$ \\
\hline & Floricultural crops & -.177 & & \\
\hline \multirow{2}{*}{ Place } & Indoor & .010 & \multirow{2}{*}{14.2} & \\
\hline & Outdoor & -.010 & & \\
\hline \multirow{2}{*}{ Time } & 30 min. & .079 & \multirow{2}{*}{16.1} & \\
\hline & $30 \sim 60 \mathrm{~min}$. & -.079 & & \\
\hline
\end{tabular}

${ }^{\mathrm{z}}$ Estimation of part utility by conjoint analysis, ${ }^{\mathrm{y}}$ Estimation of importance by conjoint analysis.

$p=.008$, Table 4). Early childhood teachers showed highest importance in what object is used in horticultural activities among fruits, vegetables and flowers, which indicates that, in designing a horticultural program, it is necessary to first consider selecting the object of horticultural activities, and then consider activity type such as big and small group, free choice, or outdoor play. Preference by level for objects was vegetable crops (part utility $[\mathrm{Pu}]=.156$ ), fruit crops $(\mathrm{Pu}=.21)$, and floricultural crops $(\mathrm{Pu}=-.177)$, indicating that the participants preferred vegetable crops most. This study classified herbal plants as horticultural plants. According to Shin et al. (2012), kindergarteners that participated in horticultural activities using herbal plants most preferred growing herbs in pots, followed by making herbal ice cream. It seems it would be desirable to use plants that are ornamental and edible like herbal plants. Preference for place of horticultural activities (14.2\%) showed the lowest importance among the attributes, proving that the venue (whether indoors or outdoors) is not a top-priority factor to consider in proposing a horticultural program for preschoolers. As for preference by level of each attribute, the teachers preferred big and small groups for type of activities, and vegetable crops for object of activities. They also preferred indoors for place, and 30 minutes for time.

\section{Preference in horticultural activities according to career experience of early childhood teachers}

As a result of analyzing preference by attribute of horticultural activities according to career experience of early childhood teachers, it was found that teachers with 4 years or less experience showed highest importance in object (26.04\%), followed by time $(25.01 \%)$, activity method (21.33\%), place (18.75\%), and activity type (8.87\%) (Table 5). Those with 5-9 years of experience showed highest importance in object $(44.25 \%)$, followed by time $(26.12 \%)$, activity method $(17.38 \%)$, place $(10.42 \%)$, and activity type (4.98\%). Those with at least 10 years of experience showed highest importance in object (51.98\%), followed by activity method $(22.85 \%)$, time $(3.91 \%)$, place $(6.28 \%)$, and activity type (4.98\%). Others showed highest importance in object $(49.12 \%)$, followed by place $(29.83 \%)$, activity type $(10.53 \%)$ activity method (5.26\%), and time (5.26\%). The importance was high in object regardless of career experience, and the percentage was $51.98 \%$ for at least 10 years of experience, $44.25 \%$ for $5-9$ years, and $26.04 \%$ for less than 4 years, indicating that teachers with more career experience tended to think that selection of the object is more important for preschoolers' horticultural activities than activity method, type, place, and time. Early childhood teachers with much career experience are also experienced with big and small group activities, free choice activities and 
Table 5. Preference of horticultural activities according to the career of kindergarten teachers

\begin{tabular}{|c|c|c|c|c|c|c|c|c|c|c|c|}
\hline \multirow{3}{*}{ Attribute } & \multirow{3}{*}{ Levels } & \multicolumn{10}{|c|}{ Career of kindergarten teachers } \\
\hline & & \multicolumn{2}{|c|}{$\begin{array}{c}4 \text { years or less } \\
(n=90)\end{array}$} & \multicolumn{2}{|c|}{$\begin{array}{l}5-9 \text { years } \\
(n=79)\end{array}$} & \multicolumn{2}{|c|}{$\begin{array}{l}\text { More than } 10 \text { years } \\
\qquad(\mathrm{n}=85)\end{array}$} & \multicolumn{2}{|c|}{$\begin{array}{l}\text { Other } \\
(\mathrm{n}=3)\end{array}$} & \multicolumn{2}{|c|}{$\begin{array}{c}\text { Total } \\
(\mathrm{n}=257)\end{array}$} \\
\hline & & $\mathrm{Pu}$ & $\mathrm{I}(\%)$ & $\mathrm{Pu}$ & $\mathrm{I}(\%)$ & $\mathrm{Pu}$ & $\mathrm{I}(\%)$ & $\mathrm{Pu}$ & $\mathrm{I}(\%)$ & $\mathrm{Pu}$ & $\mathrm{I}(\%)$ \\
\hline \multirow{2}{*}{$\begin{array}{l}\text { Activity } \\
\text { method }\end{array}$} & Horticultural activity & .0569 & \multirow{2}{*}{21.33} & .0752 & \multirow{2}{*}{17.38} & .1015 & \multirow{2}{*}{22.85} & -.0625 & \multirow{2}{*}{5.26} & .0759 & \multirow{2}{*}{21.92} \\
\hline & Integration horticultural activity & -.0569 & & -.0752 & & -.1015 & & .0625 & & -.0759 & \\
\hline \multirow{3}{*}{$\begin{array}{l}\text { Activity } \\
\text { topics }\end{array}$} & Large and small group & .0269 & \multirow{3}{*}{8.87} & .0063 & \multirow{3}{*}{1.83} & .0172 & \multirow{3}{*}{4.98} & .1667 & & .0190 & \multirow{3}{*}{4.36} \\
\hline & Free selection & -.0204 & & -.0095 & & .0098 & & .0833 & 10.53 & -.0078 & \\
\hline & Outside play & -.0065 & & .0032 & & -.0270 & & -.0833 & & -.0112 & \\
\hline \multirow{3}{*}{ Object } & Fruit crops & .0204 & \multirow{3}{*}{26.04} & -.0348 & \multirow{3}{*}{44.25} & .0804 & \multirow{3}{*}{51.98} & -.1389 & & .0214 & \multirow{3}{*}{48.02} \\
\hline & Vegetable crops & .0593 & & .2089 & & .1907 & & .6528 & 49.12 & .1556 & \\
\hline & Floricultural crops & -.0796 & & -.1741 & & -.2711 & & -.5139 & & -.1770 & \\
\hline \multirow{2}{*}{ Place } & Indoor & -.0500 & \multirow{2}{*}{18.75} & .0451 & \multirow{2}{*}{10.42} & .0279 & \multirow{2}{*}{6.28} & .3542 & $\Omega^{-}$ & .0097 & \multirow{2}{*}{2.80} \\
\hline & Outdoor & .0500 & & -.0451 & & -.0279 & & -.3542 & 29.03 & -.0097 & \\
\hline \multirow{2}{*}{ Time } & $30 \mathrm{~min}$. & .0667 & \multirow{2}{*}{25.01} & .1131 & \multirow{2}{*}{26.12} & .0618 & \multirow{2}{*}{13.91} & .0625 & 526 & .0793 & \multirow{2}{*}{22.90} \\
\hline & $30 \sim 60 \mathrm{~min}$. & -.0667 & & -.1131 & & -.0618 & & -.0625 & & -.0793 & \\
\hline
\end{tabular}

Note. $\mathrm{Pu}=$ part utility, estimation of part utility by conjoint analysis; $\mathrm{I}=$ importance, estimation of importance by conjoint analysis.

outdoor play that are commonly carried out in kindergartens, which is why the importance is measured low, whereas objects such as fruits, vegetables and flowers are considered important in horticultural activities and may change preschoolers' activities significantly, thereby giving highest importance to object. Importance was highest in object regardless of career experience of early childhood teachers, indicating that they consider object most important in choosing horticultural activities. Moreover, by level of fruits, vegetables and flowers, all of the teachers with 4 years or less experience $(\mathrm{Pu}=.0593), 5-9$ years $(\mathrm{Pu}=.2089), 10$ years or more $(\mathrm{Pu}=.1907)$, and others $(\mathrm{Pu}=.6528)$ showed higher preference for vegetable crops than fruit and floricultural crops. As a result of analyzing the current state of horticultural education and perception of early childhood teachers, it was found that teachers most preferred edible plants $(62.8 \%)$, followed by arbors and shrubs (10.5\%), and flowering plants (9.3\%) (Chi et al., 2018), which is similar to the result that preference and importance of vegetable crops, which are edible herbaceous plants, turned out to be high.

\section{Preference in horticultural activities according to education level of early childhood teachers}

As a result of analyzing preference by attribute of horticultural activities according to education level of early childhood teachers, it was found that teachers who graduated a 2 or 3-year college showed highest preference for object $(29.36 \%)$, followed by time $(28.47 \%)$, activity type (23.48\%), activity method (16.73\%), and place (1.96\%) (Table 6). Those who graduated a 4-year college showed highest preference for object $(50.40 \%)$, followed by activity type $(26.75 \%)$, activity method $(12.39 \%)$, time $(9.70 \%)$, and place $(0.76 \%)$. Those with a master's degree showed highest preference for object (51.66\%), followed by activity method (31.27\%), place (9.47\%), activity type (4.75\%), and time $(2.85 \%)$. Those with a doctoral degree showed highest preference for object (32.43\%), followed by activity method $(22.52 \%)$, place $(20.72 \%)$, activity type $(19.82 \%)$, and time $(4.50 \%)$. Others showed highest preference for activity type (32.56\%), followed by object (26.75\%), place (19.77\%), time (17.45\%), and activity method (3.48\%). All the teachers who graduated a 2 or 3-year college, a 4-year college, have a master's or doctoral degree except 'others' showed highest importance in object. By level, those who graduated a 2 or 3-year college, a 4-year college, have a 
Table 6. Preference of horticultural activities according to the educational background of kindergarten teachers

\begin{tabular}{|c|c|c|c|c|c|c|c|c|c|c|c|c|c|}
\hline \multirow{3}{*}{ Attribute } & \multirow{3}{*}{ Levels } & \multicolumn{12}{|c|}{ Educational background of kindergarten teachers } \\
\hline & & \multicolumn{2}{|c|}{$\begin{array}{l}2-3 \text { year univ. } \\
\qquad(\mathrm{n}=148)\end{array}$} & \multicolumn{2}{|c|}{$\begin{array}{l}4 \text { year univ. } \\
(\mathrm{n}=77)\end{array}$} & \multicolumn{2}{|c|}{$\begin{array}{c}\text { Master Degree } \\
\quad(\mathrm{n}=21)\end{array}$} & \multicolumn{2}{|c|}{$\begin{array}{c}\text { Doctor Degree } \\
\quad(n=5)\end{array}$} & \multicolumn{2}{|c|}{$\begin{array}{l}\text { Other } \\
(n=6)\end{array}$} & \multicolumn{2}{|c|}{$\begin{array}{c}\text { Total } \\
(\mathrm{n}=257)\end{array}$} \\
\hline & & $\mathrm{Pu}$ & $\mathrm{I}(\%)$ & $\mathrm{Pu}$ & I $(\%)$ & $\mathrm{Pu}$ & $\mathrm{I}(\%)$ & $\mathrm{Pu}$ & $\mathrm{I}(\%)$ & $\mathrm{Pu}$ & $\mathrm{I}(\%)$ & $\mathrm{Pu}$ & $\mathrm{I}(\%)$ \\
\hline \multirow{2}{*}{$\begin{array}{l}\text { Activity } \\
\text { method }\end{array}$} & Horticultural activity & .0650 & \multirow{2}{*}{16.73} & .0519 & \multirow{2}{*}{12.39} & .1964 & \multirow{2}{*}{31.27} & .3125 & \multirow{2}{*}{22.52} & .0312 & \multirow{2}{*}{3.48} & .0759 & \multirow{2}{*}{21.92} \\
\hline & Integration horticultural activity & -.0650 & & -.0519 & & -.1964 & & -.3125 & & -.0312 & & -.0759 & \\
\hline \multirow{3}{*}{$\begin{array}{l}\text { Activity } \\
\text { topics }\end{array}$} & Large and small group & .0929 & \multirow{3}{*}{23.48} & -.0979 & \multirow{3}{*}{26.75} & -.0298 & \multirow{3}{*}{4.75} & .2500 & \multirow{3}{*}{19.82} & -.3264 & & .0190 & \multirow{3}{*}{4.36} \\
\hline & Free selection & -.0034 & & -.0281 & & .0000 & & .0500 & & .0694 & 32.56 & -.0078 & \\
\hline & Outside play & -.0895 & & .1261 & & .0298 & & -.3000 & & .2569 & & -.0112 & \\
\hline \multirow{3}{*}{ Object } & Fruit crops & -.0225 & \multirow{3}{*}{29.36} & .0346 & \multirow{3}{*}{50.40} & .2381 & \multirow{3}{*}{51.66} & .0167 & \multirow{3}{*}{32.43} & .1806 & & .0214 & \multirow{3}{*}{48.02} \\
\hline & Vegetable crops & .1253 & & .1937 & & .1726 & & .4417 & & .1181 & 26.75 & .1556 & \\
\hline & Floricultural crops & -.1028 & & -.2284 & & -.4107 & & -.4583 & & -.2986 & & -.1770 & \\
\hline \multirow{2}{*}{ Place } & Indoor & .0076 & \multirow{2}{*}{1.96} & -.0032 & \multirow{2}{*}{0.76} & .0595 & \multirow{2}{*}{9.47} & .2875 & \multirow{2}{*}{20.72} & -.1771 & 1077 & .0097 & \multirow{2}{*}{2.80} \\
\hline & Outdoor & -.0076 & & .0032 & & -.0595 & & -.2875 & & .1771 & & -.0097 & \\
\hline \multirow{2}{*}{ Time } & $30 \mathrm{~min}$. & .1106 & 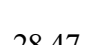 & .0406 & 070 & -.0179 & 285 & .0625 & 450 & .1563 & 1745 & .0793 & 200 \\
\hline & $30 \sim 60 \mathrm{~min}$. & -.1106 & & -.0406 & & .0179 & & -.0625 & & -.1563 & & -.0793 & \\
\hline
\end{tabular}

Note. $\mathrm{Pu}=$ part utility, estimation of part utility by conjoint analysis; $\mathrm{I}=$ importance, estimation of importance by conjoint analysis.

doctoral degree preferred vegetable crops, while those who have a master's degree preferred fruit crops. As for activity method, teachers in all education levels preferred exclusive horticultural activities to integrated activities. As a result of analyzing the current state of horticultural education for preschoolers and perception of teachers, it was found that at least a majority of institutions for early childhood education preferred to integrate horticultural education with science or other subjects rather than providing it separately on its own (Chi et. al., 2018), which is different from the result of this study. In this study, teachers preferred to have horticultural activities separately as a single class, which is due to the improved awareness and importance of horticultural activities. All the teachers turned out to prefer exclusive horticultural activities: 2 or 3-year college $(\mathrm{Pu}=.0650)$, 4-year college $(\mathrm{Pu}=.0519)$, master's degree $(\mathrm{Pu}=.1964)$, and doctoral degree $(\mathrm{Pu}=.3125)$. This shows that teachers with a master's degree and doctoral degree more prefer exclusive horticultural activities than those who graduated a 2 or 3-year college and a 4-year college, showing a difference depending on education level. As for time, teachers with a master's degree preferred 30-60 minutes, while those who graduated a 2 or 3-year college and a 4-year college, those with a doctoral degree, and others preferred $30 \mathrm{mi}-$ nutes, showing a difference depending on education level.

\section{Preference in horticultural activities according to workplace of early childhood teachers}

The Nuri Curriculum is a national-level curriculum comprised of five key areas such as physical exercise/health, communication, social relationship, artistic experience, and nature exploration, designed to promote basic abilities and upright character necessary for 5-year-old children (MEST, 2012). Currently, both kindergartens and daycare centers are adopting the Nuri Curriculum as a regular curriculum. As a result of analyzing preference by attribute of horticultural activities according to workplace of early childhood teachers, it was found that public kindergarten teachers showed highest importance in activity method (35.83\%), followed by time $(19.17 \%)$, activity type $(17.50 \%)$, place (14.16\%), and object (13.33\%) (Table 7). Private kindergarten teachers showed highest importance in object (35.39\%), followed by time (28.21\%), activity method (17.87\%), activity type $(15.70 \%)$, and place $(2.83 \%)$. As a result of examining the importance perceived by daycare center teachers, they showed highest importance in object (53.44\%), followed by time (20.64\%), activity method (18.58\%), place (4.59\%), and activity type (2.75\%). All of public kindergarten, pri- 
Table 7. Preference of horticulture activities according to the type of kindergarten

\begin{tabular}{|c|c|c|c|c|c|c|c|c|c|}
\hline \multirow{3}{*}{ Attribute } & \multirow{3}{*}{ Levels } & \multicolumn{8}{|c|}{ Type of kindergarten } \\
\hline & & \multicolumn{2}{|c|}{$\begin{array}{l}\text { Public kindergarten } \\
\qquad(\mathrm{n}=13)\end{array}$} & \multicolumn{2}{|c|}{$\begin{array}{l}\text { Private kindergarten } \\
\qquad(\mathrm{n}=126)\end{array}$} & \multicolumn{2}{|c|}{$\begin{array}{l}\text { Child Care Center } \\
\qquad(\mathrm{n}=118)\end{array}$} & \multicolumn{2}{|c|}{$\begin{array}{c}\text { Total } \\
(\mathrm{n}=257)\end{array}$} \\
\hline & & $\mathrm{Pu}$ & $\mathrm{I}(\%)$ & $\mathrm{Pu}$ & $\mathrm{I}(\%)$ & $\mathrm{Pu}$ & $\mathrm{I}(\%)$ & $\mathrm{Pu}$ & $\mathrm{I}(\%)$ \\
\hline \multirow{2}{*}{$\begin{array}{l}\text { Activity } \\
\text { method }\end{array}$} & Horticultural activity & .2067 & \multirow{2}{*}{35.83} & .0531 & \multirow{2}{*}{17.87} & .0858 & \multirow{2}{*}{18.58} & .0759 & \multirow{2}{*}{21.92} \\
\hline & Integration horticultural activity & -.2067 & & -.0531 & & -.0858 & & -.0759 & \\
\hline \multirow{3}{*}{$\begin{array}{l}\text { Activity } \\
\text { topics }\end{array}$} & Large and small group & -.0353 & \multirow{3}{*}{17.50} & .0450 & \multirow{3}{*}{15.70} & -.0028 & & .0190 & \multirow{3}{*}{4.36} \\
\hline & Free selection & -.0833 & & .0033 & & -.0113 & 2.75 & -.0078 & \\
\hline & Outside play & .1186 & & -.0483 & & .0141 & & -.0112 & \\
\hline \multirow{3}{*}{ Object } & Fruit crops & .0833 & \multirow{3}{*}{13.33} & -.0245 & \multirow{3}{*}{35.39} & .0636 & & .0214 & \multirow{3}{*}{48.02} \\
\hline & Vegetable crops & -.0128 & & .1174 & & .2150 & 53.44 & .1556 & \\
\hline & Floricultural crops & -.0705 & & -.0929 & & -.2786 & & -.1770 & \\
\hline \multirow{2}{*}{ Place } & Indoor & .0817 & \multirow{2}{*}{14.16} & -.0084 & \multirow{2}{*}{2.83} & .0212 & 450 & .0097 & \multirow{2}{*}{2.80} \\
\hline & Outdoor & -.0817 & & .0084 & & -.0212 & 4.59 & -.0097 & \\
\hline \multirow{2}{*}{ Time } & $30 \mathrm{~min}$. & -.1106 & \multirow{2}{*}{19.17} & .0838 & \multirow{2}{*}{28.21} & .0953 & 2064 & .0793 & \multirow{2}{*}{22.90} \\
\hline & $30 \sim 60 \mathrm{~min}$. & .1106 & & -.0838 & & -.0953 & 20.04 & -.0793 & \\
\hline
\end{tabular}

Note. $\mathrm{Pu}=$ part utility, estimation of part utility by conjoint analysis; $\mathrm{I}=$ importance, estimation of importance by conjoint analysis.

vate kindergarten, and daycare center teachers preferred exclusive horticultural activities, which is the same case as career experience and education level of the teachers and is related to the increase in the awareness and interest for horticultural activities. However, an additional survey must be conducted to verify the specific reasons. There was no consistency in preference for activity type, object, place, and time among public kindergarten, private kindergarten, and daycare center teachers.

\section{Preference in horticultural activities according to certificate of early childhood teachers}

If one has a Teacher Level 2 certificate and at least 3 years of field experience, he or she is qualified to receive Teacher Level 1 training, after which he or she is promoted to Teacher Level 1 ( $\mathrm{Im}$ and Lee, 2011). As a result of analyzing preference in horticultural activities according to certificate, it was found that Teacher Level 1 showed highest importance in object (46.16\%), followed by activity method (31.03\%), time $(21.73 \%)$, place $(8.15 \%)$, and activity type (2.94\%) (Table 8). Teacher Level 2 showed highest importance in object (45.09\%), followed by time (20.78\%), activity method (19.49\%), activity type $(9.34 \%)$, and place (5.31\%). Both Teacher Level 1 and Teacher Level 2 con- sidered object as the most important attribute. By level, the preference was highest for vegetable crops. As for the second-highest preference, Teacher Level 1 preferred activity type, and Teacher Level 2 preferred time, showing a difference between the two.

\section{Preference in horticultural activities according to the age of children in class}

As a result of analyzing preference of horticultural activities according to the age of children in class which the teachers are in charge of, it was found that the teachers in charge of a 3-year-old class showed highest importance in object (38.83\%), followed by activity method (27.56\%), place $(12.57 \%)$, time $(12.35 \%)$, and activity type $(8.66 \%)$ (Table 9). Those in charge of a 4-year-old class showed highest importance in time (50.37\%), followed by place (20.31\%), activity type (8.27\%), and activity method (1.50\%). Those in charge of a 5-year-old class showed highest importance in object $(65.53 \%)$, followed by time $(16.59 \%)$, activity method $(9.94 \%)$, place $(6.15 \%)$, and activity type $(3.79 \%)$. For time, all of the teachers in charge of a 3-year-old class, 4-year-old class, and 5-year-old class preferred 30 minutes. This is a result of considering the time in which preschoolers can concentrate. 
Table 8. Preference of horticultural activities according to kindergarten teacher's certificate

\begin{tabular}{|c|c|c|c|c|c|c|c|c|c|}
\hline \multirow{3}{*}{ Attribute } & \multirow{3}{*}{ Levels } & \multicolumn{8}{|c|}{ T eacher's certificate } \\
\hline & & \multicolumn{2}{|c|}{$\begin{array}{c}\text { Level } 1 \\
\text { Orthodox Teacher } \\
(\mathrm{n}=124)\end{array}$} & \multicolumn{2}{|c|}{$\begin{array}{c}\text { Level } 2 \\
\text { Orthodox teacher } \\
\quad(\mathrm{n}=132)\end{array}$} & \multicolumn{2}{|c|}{$\begin{array}{l}\text { Other } \\
(n=1)\end{array}$} & \multicolumn{2}{|c|}{$\begin{array}{c}\text { Total } \\
(\mathrm{n}=257)\end{array}$} \\
\hline & & $\mathrm{Pu}$ & $\mathrm{I}(\%)$ & $\mathrm{Pu}$ & $\mathrm{I}(\%)$ & $\mathrm{Pu}$ & $\mathrm{I}(\%)$ & $\mathrm{Pu}$ & $\mathrm{I}(\%)$ \\
\hline \multirow{2}{*}{$\begin{array}{l}\text { Activity } \\
\text { method }\end{array}$} & Horticultural activity & .0937 & \multirow{2}{*}{31.03} & .0573 & \multirow{2}{*}{19.49} & .3125 & \multirow{2}{*}{17.86} & .0759 & \multirow{2}{*}{17.11} \\
\hline & Integration horticultural activity & -.0937 & & -.0573 & & -.3125 & & -.0759 & \\
\hline \multirow{3}{*}{$\begin{array}{l}\text { Activity } \\
\text { topics }\end{array}$} & Large and small group & -.0007 & \multirow{3}{*}{2.94} & .0303 & \multirow{3}{*}{9.34} & .9583 & & .0190 & \multirow{3}{*}{3.40} \\
\hline & Free selection & .0134 & & -.0246 & & -.4167 & 42.86 & -.0078 & \\
\hline & Outside play & -.0128 & & -.0057 & & -.5417 & & -.0112 & \\
\hline \multirow{3}{*}{ Object } & Fruit crops & -.0054 & \multirow{3}{*}{46.16} & .0448 & \multirow{3}{*}{45.09} & .2500 & & .2500 & \multirow{3}{*}{48.14} \\
\hline & Vegetable crops & .2083 & & .1102 & & -.3750 & 17.86 & .1556 & \\
\hline & Floricultural crops & -.2030 & & -.1550 & & .1250 & & -.1770 & \\
\hline \multirow{2}{*}{ Place } & Indoor & .0363 & \multirow{2}{*}{8.15} & -.0156 & \multirow{2}{*}{5.31} & .0625 & 25 & .0097 & \multirow{2}{*}{2.19} \\
\hline & Outdoor & -.0363 & & .0156 & & -.0625 & I & -.0097 & \\
\hline \multirow{2}{*}{ Time } & $30 \mathrm{~min}$. & .0968 & \multirow{2}{*}{21.73} & .0611 & \multirow{2}{*}{20.78} & .3125 & 1786 & .1793 & \multirow{2}{*}{29.15} \\
\hline & $30 \sim 60 \mathrm{~min}$. & -.0968 & & -.0611 & & -.3125 & & -.0793 & \\
\hline
\end{tabular}

Note. $\mathrm{Pu}=$ part utility, estimation of part utility by conjoint analysis; $\mathrm{I}=$ importance, estimation of importance by conjoint analysis.

Table 9. Preference of horticulture activities by kindergarten teachers according to age of kindergarten students in charge

\begin{tabular}{|c|c|c|c|c|c|c|c|c|c|c|c|}
\hline \multirow{3}{*}{ Attribute } & \multirow{3}{*}{ Levels } & \multicolumn{10}{|c|}{ Age of kindergarteners } \\
\hline & & \multicolumn{2}{|c|}{$\begin{array}{c}3 \text { years } \\
(n=121)\end{array}$} & \multicolumn{2}{|c|}{$\begin{array}{l}4 \text { years } \\
(\mathrm{n}=51)\end{array}$} & \multicolumn{2}{|c|}{$\begin{array}{l}5 \text { years } \\
(n=84)\end{array}$} & \multicolumn{2}{|c|}{$\begin{array}{l}\text { Other } \\
(n=1)\end{array}$} & \multicolumn{2}{|c|}{$\begin{array}{c}\text { Total } \\
(\mathrm{n}=257)\end{array}$} \\
\hline & & $\mathrm{Pu}$ & $\mathrm{I}(\%)$ & $\mathrm{Pu}$ & $\mathrm{I}(\%)$ & $\mathrm{Pu}$ & $\mathrm{I}(\%)$ & $\mathrm{Pu}$ & $\mathrm{I}(\%)$ & $\mathrm{Pu}$ & I $(\%)$ \\
\hline \multirow{2}{*}{$\begin{array}{l}\text { Activity } \\
\text { method }\end{array}$} & Horticultural activity & .1348 & \multirow{2}{*}{27.56} & .0049 & \multirow{2}{*}{1.50} & .0312 & \multirow{2}{*}{9.94} & .3125 & \multirow{2}{*}{17.59} & .0759 & \multirow{2}{*}{21.92} \\
\hline & Integration horticultural activity & -.1348 & & -.0049 & & -.0312 & & -.3012 & & -.0759 & \\
\hline \multirow{3}{*}{$\begin{array}{l}\text { Activity } \\
\text { topics }\end{array}$} & Large and small group & .0530 & \multirow{3}{*}{8.66} & -.0310 & \multirow{3}{*}{8.27} & -.0109 & \multirow{3}{*}{3.79} & .9583 & & .0190 & \multirow{3}{*}{4.36} \\
\hline & Free selection & -.0213 & & .0229 & & -.0020 & & -.4167 & 43.00 & -.0078 & \\
\hline & Outside play & -.0317 & & .0082 & & .0129 & & -.5417 & & -.0112 & \\
\hline \multirow{3}{*}{ Object } & Fruit crops & .0324 & \multirow{3}{*}{38.86} & -.0359 & \multirow{3}{*}{19.56} & .0377 & \multirow{3}{*}{65.53} & .2500 & & .0214 & \multirow{3}{*}{48.02} \\
\hline & Vegetable crops & .1739 & & .0817 & & .1806 & & -.3750 & 17.91 & .1556 & \\
\hline & Floricultural crops & -.2063 & & -.0458 & & -.2183 & & .1250 & & -.1770 & \\
\hline \multirow{2}{*}{ Place } & Indoor & .0615 & \multirow{2}{*}{12.57} & -.0662 & \multirow{2}{*}{20.31} & -.0193 & \multirow{2}{*}{6.15} & .0625 & 358 & .0097 & \multirow{2}{*}{2.80} \\
\hline & Outdoor & -.0615 & & .0662 & & .0193 & & -.0625 & & -.0097 & \\
\hline \multirow{2}{*}{ Time } & $30 \mathrm{~min}$. & .0604 & \multirow{2}{*}{12.35} & .1642 & \multirow{2}{*}{50.37} & .0521 & \multirow{2}{*}{16.59} & .3125 & 1791 & .0793 & \multirow{2}{*}{22.90} \\
\hline & $30 \sim 60 \mathrm{~min}$. & -.0604 & & -.1642 & & -.0521 & & -.3125 & & -.0793 & \\
\hline
\end{tabular}

Note. $\mathrm{Pu}=$ part utility, estimation of part utility by conjoint analysis; $\mathrm{I}=$ importance, estimation of importance by conjoint analysis.

\section{Conclusion}

Most studies analyzed the current state of horticultural education for preschoolers and the perception of teachers by deriving survey items and analyzing the responses pro- vided by the respondents, but this study examined and analyzed the preference of early childhood teachers in horticultural activities through conjoint analysis. Conjoint analysis is a typical method used to analyze consumer utility in marketing, predicting the product that will be chosen by 
the customer by estimating the utility given to each attribute of the product. There are other cases in which conjoint analysis is used aside from marketing, such as measuring the economic value of improving accuracy of the weather system and forecasting model, and studying the selection factors for global cold chain transport route using conjoint analysis. This study revised the attributes according to the level of preschoolers based on the importance of horticultural activities presented by previous studies, thereby extracting five attributes and selecting the levels for each attribute. Attribute 1 is method of horticultural activities, divided into two levels: exclusive horticultural activities and integrated horticultural activities. Attribute 2 is object of horticultural activities, divided into three levels: fruit crops, vegetable crops, and floricultural crops. Attribute 3 is activity type, divided into three levels presented in the analysis of horticultural activities in the 5-year-old Nuri Curriculum teacher's guidebook: big and small group, free choice, and outdoor play. Attribute 4 is place of activities, divided into two levels: indoors and outdoors. Attribute 5 is time for activities, divided into two levels: 30 minutes and 30-60 minutes. The orthogonal design was used to extract 20 profiles, after which we conducted a survey on 320 early childhood teachers and analyzed the valid responses from 257 teachers.

The preference of early childhood teachers showed highest importance in object (29.1\%), followed by activity type (23.2\%), activity method (17.4\%), time (16.1\%), and place (14.2\%) (Pearson's $\mathrm{R}=.591, p=.008$, Table, 4). By level of each attribute, the importance was high in exclusive horticultural activities for activity method, big and small group for activity type, vegetable and floricultural crops for object, indoors for place, and 30 minutes for time. In sum, the horticultural program preferred by early childhood teachers is comprised of big and small group activities using vegetable and floricultural crops, carried out indoors for 30 minutes as an exclusive class.

This study has significance in that, first, it has examined and analyzed the preference of early childhood teachers in horticultural activities using conjoint analysis. We could determine the attributes and levels preferred by early childhood teachers in horticultural activities by setting the attributes and levels of activities and conducting a survey based on conjoint analysis. Second, the results can be used as the basic data for developing a horticultural program, which is insufficient in the Nuri Curriculum that is a regular curriculum for preschoolers. Further research must be conducted to develop a horticultural program based on the Nuri Curriculum using the results of this study and validate the program with preschoolers at an actual institution for early childhood education.

\section{References}

Chi, S.A., C.Y. Kim, and J.H. Jung. 2018. An analysis of the status and teachers awareness of horticulture education for young children. Early Child. Educ. Res. Rev. 22(5):191-217. https://doi.org/10.32349/ECERR.2 018.10.22.5.191

Choi B.J., Y.J. Jeong, M.J. Kim and S.Y. Yun. 2020. Analysis of horticultural activities in the teacher's guide books of Nuri curriculum for 5-Year-Olds. J. People Plant Environ. 23(2):211-220. https://doi.org/10.11628/ ksppe.2020.23.2.211

Cho, Y.M., D.J. Kim, P.S. Yeoun, H.E. Lee, K.H. Lee, K.T. Park, E. J. Lee and B.B. Lee, 2016, A meta-analysis for the effect of forest experience on young children: Effect size on the moderating variables. J. Korean For. Soc. 105(1):139-148. https://doi.org/10.14578/jkfs.2016. 105.1.139

Ha, C.S. 2012. The validity of conjoint models with the attributes and their levels determined by the respondents. Doctoral dissertation, Kyung Hee University, Suwon, Korea.

Heo, P.K. 2015. The study on effective conjoint analysis method using a computer-based interactive information gathering methods. Doctoral dissertation, Kyung Hee University, Suwon, Korea.

Im J.Y and D.K. Lee. 2011. Exploring the process of group discussion in the first degree kindergarten teachers' qualification training. Early Child. Educ. Res. Rev. 15(2): 393-418.

Jang, E.J. G.W.Han, J.W. Hong, S.E. Yoon and C.H. Park. 2010. Meta-analysis of research papers on horticultural therapy program effect. Korean J. Hortic. Sci. Technol. 28(4):701-707. 
Jang, H.H., M.I. Kim, S.Y. Yun and B.J. Choi. 2019. The effects of play activities in forest on the emotional vocabulary change of children. J. Korean Soc. Flor. Art Des. 41(41):3-12.

Jang, J.Y. and K.S. Chung. 2018. A study on the effectiveness of play activities in forest to improve children's community spirit. J. Korea Open Assoc. Early Child. Educ. 23(5): 269-292. https://doi.org/10.20437/KOAECE23-5-12

Jeong, M.I., E.S. Jea, S.M. Lee, and B.Y. Yi. 2014. Effects of horticultural activities program focusing on fourseason ornamental rooftop garden to be released on preschoolers' creative thinking. J. Korean Soc. People Plant Environ. 17(1):9-14. https://doi.org/10.11628/kspp e.2014.17.1.009

Jeong, S.J., Y.J. Song, M.S. Kim, M.I. Jeong and H.D. Kim. 2009. Effect of young children's horticultural program on the young children's natural- environment attitude, scientific attitude and exploration ability, and emotional intelligence. J. Korean Soc. People Plants Environ. 12(6):37-43.

Jung, S.J., K.S. Eom, and B.S. Kim. 2017. The effect of horticultural activities of early childhood infants on emotional intelligence, peer competence, and self-esteem. J. Eco Early Child. Educ. Care 16(4):127-149.

Kang, H.K. 2016. The invention of forest personality activity program connected with day care center and experience of the activity by pre-service early childhood teachers. J. Future Early Child. Educ. 23(2):205-229.

Kang, Y.S. and J. H. Park. 2010. The effect of the program of ecological experience on the emotional intelligence of young children. J. Korea Acad. Ind. Coop. Soc. 11(10):3680-3687.

Kim, H.J. 2015. The effects of an art-horticulture integrated program on physically handicapped young children's self concept and interpersonal relationship. Korean J. Child. Media 14(4):25-44

Kim, J.S. 2010. Application of the horticultural therapy activity to the curriculum of korean kindergarten. J. Eurasian Stud. 7(1):281-300.

Kim, M.J., H.H. Jang, S.Y. Yun, and B.J. Choi. 2019. An analysis of research trends in forest play activities for children. J. Korean Soc. Flor. Art Des. 41(41):13-24.
Kim, S.J. and S.O. Woo. 2014. Analysis of educational content related to the environment shown in the 5- year nuri-curriculum manual for kindergarten teachers. Early Child. Educ. Res. Rev. 18(1):365-386.

Lee, I.W. 2014. The effects of forest experience activities upon young children's daily stress reduction. J. Korea Open Assoc. Early Child. Educ. 19(6):83-103.

Lee, M.H. 2011. Teachers' cognition of forest experience education in early childhood educational institutions. J. Eco Early Child. Educ. Care 10(1):175-200.

Lee, Y.M. and Y.O. Jeong. 2018. A meta- analysis of the effects of horticulture program in schools - focusing on master and doctoral dissertation in korea. J. Korean Pract. Arts Educ. 31(4):17-41. https://doi.org/10.24062/kpae.2 018.31.4.17

Lee, B.N. and M.S. Choi. 2015. The effects of activities through a forest experience on young children's scientific inquiry ability and life respect attitude. J. Parent Educ. 7(1):53-66.

Ministry of Education Science and Technology. 2007. Explanation of Kindergarten Curriculum. Seoul: Ministry of Education Science and Technology.

Ministry of Education Science and Technology. 2012. Nuricurriculum for 5-year-old. Seoul: Ministry of Education Science and Technology.

Park, S.H. and M.R. Huh. 2010. Effect of a horticultural program on the preschool children's emotional intelligence and daily stress. Korean J. Hortic. Sci. Technol. 28(1): 144-149.

Shin S.H., M.S. Cho, and T.Y. Kim. 2012. Response to horticultural activities using herb plants of kindergarten children. J. Korean Soc. People Plant Environ. 15(1):1-8.

Son, H.J., J.E. Song, and K.C. Son. 2015. Horticultural activities using colorful food for the improvement of emotional intelligence and the reduction of unbalanced vegetable diet of young children. Korean J. Hortic. Sci. Technol. 33(5):772-783.

Yun, S.Y., G.A. Seol, H.H. Jang, M. J. Kim and B. J. Choi. 2019. Forest activities for developing emotional vocabulary and lowering cortisol levels in kindergarteners. J. People Plants Environ. 22(4):385-393. https://doi.org/ 10.11628/ksppe.2019.22.4.385 